\title{
MicroscopyPioneers
}

\section{Pioneers in Fluorescence Spectroscopy: Gregorio Weber}

\author{
Cameron Varano \\ The Pennsylvania State University, 201 Old Main, University Park, PA 16802
}

cvarano@psu.edu

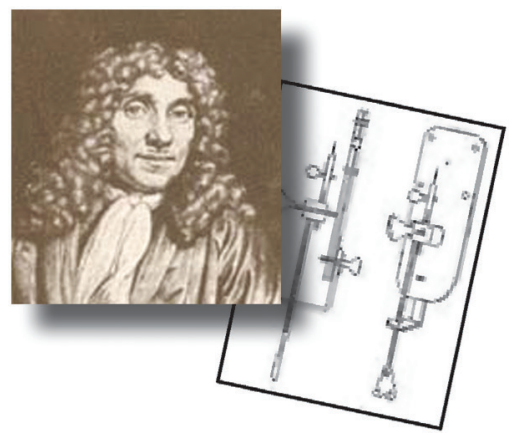

\section{Gregorio Weber \\ (1916-1997)}

Born in Argentina, Gregorio Weber began his collegiate education at the University of Buenos Aires in his hometown. There he completed a medical degree in 1942 and carried out a teaching assistantship under Bernardo Houssay, who would become a Nobel laureate. Houssay nominated Weber for a British Council Fellowship, which he won, enabling Weber to pursue gradu-

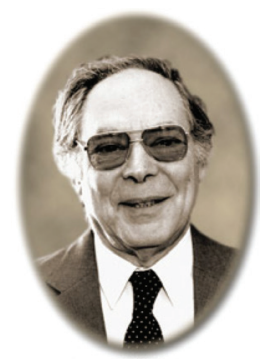
ate studies at Cambridge University. At Cambridge, Weber's thesis advisor suggested he study the fluorescence of flavins and flavoproteins, which was the beginning of a long and successful career that resulted in Weber becoming widely recognized as the founder of modern fluorescence spectroscopy.

After he received his doctorate in chemistry, Weber remained at Cambridge carrying out independent research until 1953, when he accepted a position in the new biochemistry department at Sheffield University. His years at the academic institution were marked by many pioneering efforts, which he later continued at the University of Illinois at UrbanaChampaign. Some of the many groundbreaking developments that Weber developed in the field of fluorescence include the introduction of fluorescence polarization as a method to study macromolecular dynamics, the creation of the first broadly utilized phase-modulation fluorometer, and the presentation of the first report regarding the classical technique of measuring the absolute quantum yield of fluorescence. He also recognized the importance of fluorescent probes and carried out extensive research in probe chemistry, developed high-pressure fluorescence spectroscopy as a way to examine biological membranes and proteins, formulated the addition law of fluorescence polarization, and characterized the ultraviolet fluorescence of the aromatic amino acids.

In the realm of protein chemistry Weber's work was also highly influential. While still at Cambridge, he synthesized dansyl chloride for use in his studies, a compound that has become one of the most heavily used reagents in protein chemistry. Later he became one of the first scientists to work in the field of protein dynamics, realizing as early as the 1960s that proteins were not rigid, unchanging entities. Weber also introduced physical techniques that continue to be popularly used in the field, as well as the concept of standard free energy couplings between pairs of bound ligands (ions, molecules, or molecular groups that bind to another chemical unit to fashion a larger complex), which changed the way many protein chemists think about proteins and allosteric interactions.

Weber was highly esteemed by his colleagues and received many honors during his lifetime. He was elected a member of the United States National Academy of Sciences and the American Academy of Arts and Sciences, as well as a corresponding member of The National Academy of Exact Sciences of Argentina. The first recipient of both the American Chemical Society's Repligen Award for the Chemistry of Biological Processes and the International Jablonski Award for Fluorescence Spectroscopy, Weber was also bestowed the ISCO award for Excellence in Biochemical Instrumentation and the Rumford Premium of the American Academy of Arts and Sciences. After a struggle with leukemia, Weber passed away on July 18, 1997, but his pioneering efforts paved the way for others to travel, many of whom are expanding the innovative work that he began.

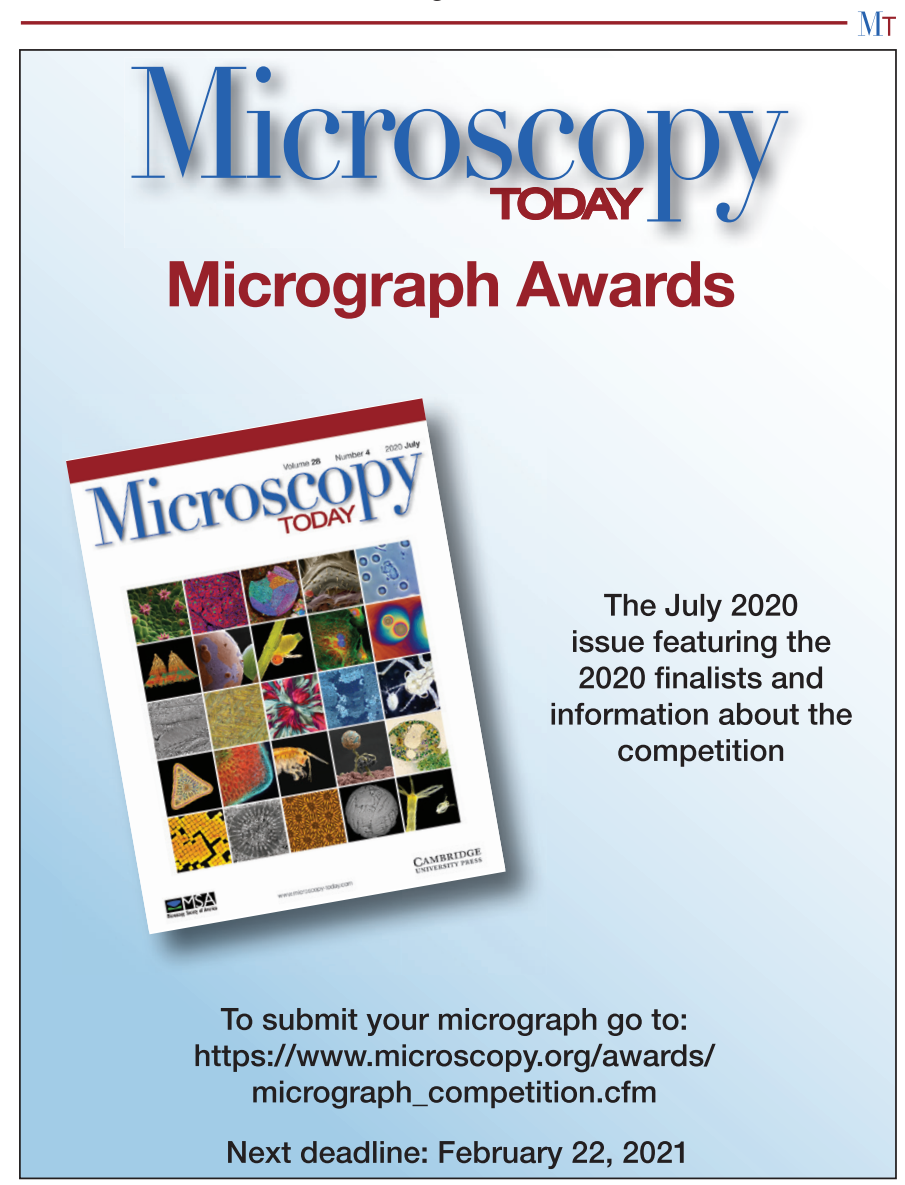



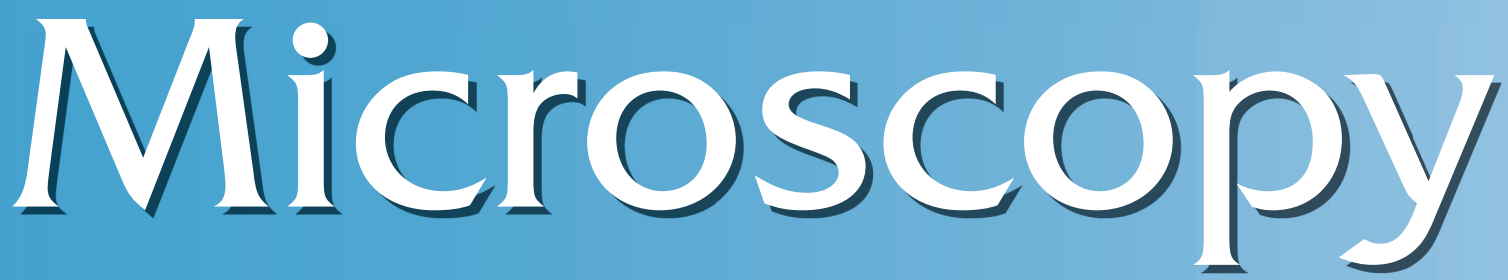

AND

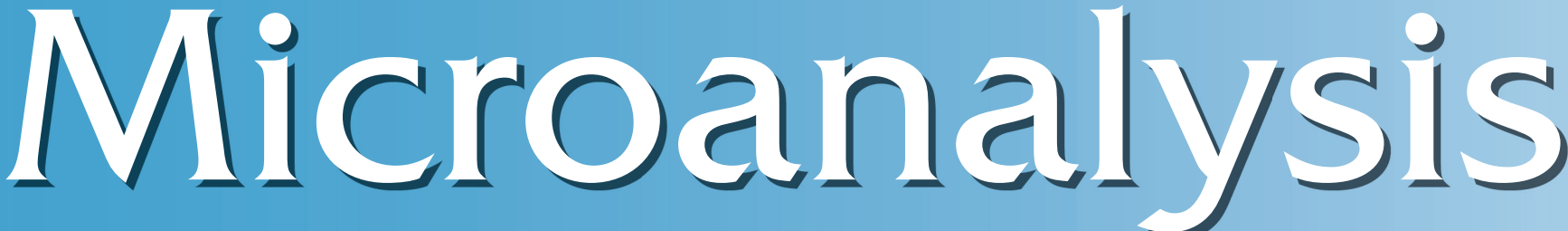

2.673

2018 Impact Factor

1 out of 9 Microscopy Journals

2018 Journal Citation Reports

(C) Clarivate Analytics

Published for the

Microscopy Society of America

Editor Dr John Mansfield

Microscopy and Microanalysis publishes

original research papers in the fields of microscopy, imaging, and compositional analysis. This distinguished international forum is intended for microscopists in both biology and materials science.

Online submission at

http://mc.manuscriptcentral.com/mam
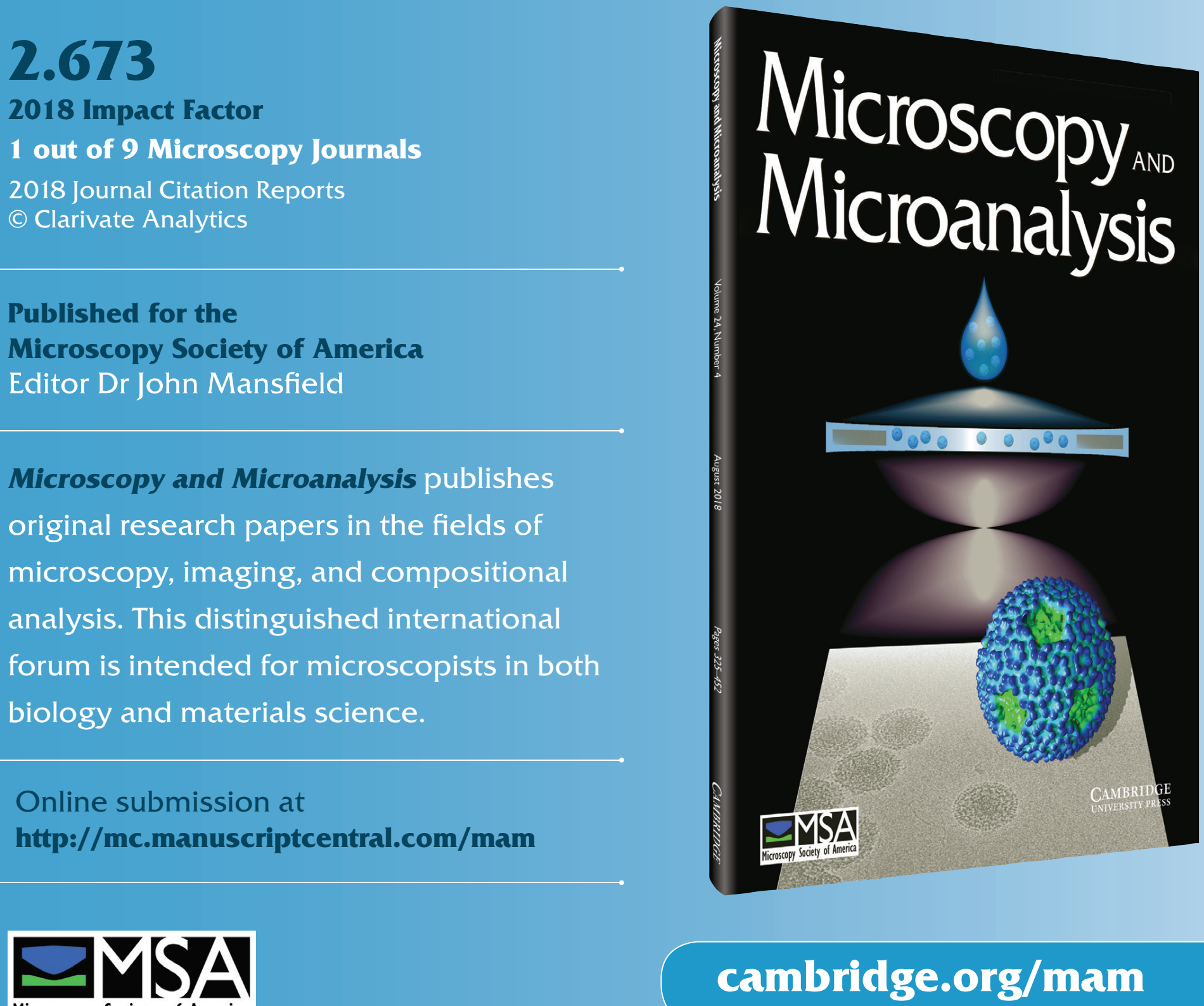

Microscopy Society of America

\section{cambridge.org/mam}

